\title{
A Figura do Demiurgo no Timeu de Platão
}

\author{
Camila Souza Lima*
}

\begin{abstract}
RESUMO
O presente trabalho tem como objetivo fazer uma exposição da figura do demiurgo em Platão, especialmente através do diálogo Timeu. 0 demiurgo constitui papel central de atuação no processo de fabricação do cosmos, trata-se de uma inteligência ordenadora da matéria disforme em um mundo de ordem e beleza. Delimitamos a interpretação da narrativa levando exclusivamente em consideração aqueles intérpretes da leitura não-literal do texto. Também levamos em consideração, através de simplificada explicação, a base ontológica e epistemológica em que Platão alicerçou a função demiúrgica. E então, fazemos a exposição das características e elementos do demiurgo em si, como causa do mundo e sua atuação, e também a importância dada ao aspecto do demiurgo enquanto inteligência. Compreendemos que Platão valeu-se de uma metáfora artesanal, miticamente simbolizada pelo deus-artesão, para a explicação da atuação de uma inteligência (noûs) ordenadora do cosmos.
\end{abstract}

Palavras-chave: Platão. Timeu. Demiurgo. Deus-artesão. Cosmos.

\begin{abstract}
The present work aims to make an exposition of the figure of the demiurge in Plato, especially through Timaeus dialogue. The demiurge plays a central role in the process of manufacturing of the cosmos. It is an intelligence that orders deformed matter into a world of order and beauty. We delimit the interpretation
\end{abstract}

* Universidade Metodista de São Paulo. camila_souza_lima@hotmail.com> 
of the narrative taking exclusively into account those interpreters of the non-literal reading of the text. We also take into account, by means of a simplified explanation, the ontological and epistemological basis on which Plato founded the demiurgical function. After that, we expose the main characteristics and elements of the demiurge itself as the cause of the sensitive world and its role in its manufacture, as well as the importance given to the demiurge's aspect as an intelligence. We understand that Plato made use of an artisanal metaphor, mythically symbolized by the artisan god, to explain the performance of an ordering intelligence (noûs) of the cosmos.

Keywords: Plato. Timaeus. Demiurge. Artisan god. Cosmos.

\section{CONSIDERAÇõES INICIAIS}

0 presente artigo tem como objetivo geral fazer uma exposição simples da figura do demiurgo de Platão, sob o intuito de trazer à tona o valor e a importância que, acreditamos, o demiurgo tem dentro da filosofia platônica.

O demiurgo aparece em diferentes diálogos do referido filósofo, mas mais especificamente no Timeu ${ }^{1}$, obra em que a sua figura é delineada a partir de uma narrativa cosmológica. 0 discurso do Timeu é uma elaborada explicação da formação do universo como ordem e beleza. Timeu propõe que esse universo seja o produto de um agente racional, intencionado e benéfico. De modo que, o arranjo cósmico não é obra ocasional, fortuita, mas produto de uma deliberada intenção do Intelecto (noûs) através de um deus antropomorficamente representado pela figura do deus-artesão.

\section{LEITURA LITERAL E NÃO-LITERAL}

Ao buscar por uma explicação que pretendesse ser fixa e blindada de ambiguidades quanto a figura demiúrgica e seu papel na filosofia platônica, pudemos perceber ser audaciosa qualquer tentativa de constatação última da figura do demiurgo. Isso ocorre, em parte, devido às divergentes linhas interpretativas do pensamento platônico

1 Diálogo com longo monólogo do personagem-título sobre a natureza do mundo físico e dos seres humanos. Acredita-se que tenha sido produzido no período mais tardio. 
que resultam em compreensões diferentes entre si e em deslocamentos da própria estrutura onto-epistemológica ${ }^{2}$ a qual a figura do Demiurgo fora alicerçada por Platão. Em outras palavras, ocorre que, a depender da linha interpretativa escolhida, há um ou outro tipo possível de delineação da figura demiúrgica. Vale dizer que essa condição de deslocamento é uma via de mão dupla; ou seja, dependendo também da forma como o demiurgo é interpretado, resulta-se, daí, uma modificação de interpretação da própria concepção ontológica de Platão, como devidamente alertado por Brisson, que qualquer "modificação da concepção da natureza do demiurgo implica uma revisão completa da ontologia platônica." (1998, p. 30)³. Ou seja, só é possível traçar um esboço ausente de ambiguidades de sua figura desde que respeitados certos pressupostos interpretativos de leitura.

Portanto, o cuidado aqui é por escolher uma única linha interpretativa do Timeu, pois, no que tange a sua investigação e aferição, deparamo-nos frente à duas vertentes interpretativas: a literal e a não-literal.

Para aqueles que defendem a literalidade do texto, a cosmologia deve ser entendida como um processo de criação do universo realizado por uma entidade antropomórfica dentro de um determinado momento no tempo. Ou seja, segundo essa interpretação, ao demiurgo é conferido o estatuto de entidade antropomórfica.

Já os que defendem a não-literalidade interpretativa entendem que o cosmos devém, porém, não de forma pontual no tempo mas de forma processual e contínua, a qual Brisson denominou de "geração ontológica” (BRISSON, 1974 apud MANINI, 2014). Essa geração é o processo de um eterno vir-a-ser reproduzido de maneira atemporal, uma vez que o universo nunca foi de fato "criado" ou "fabricado", mas sempre existiu. Segundo essa interpretação o demiurgo é entendido como uma função, sob o aspecto metafórico do deus-artesão.

2 Não nos ateremos, no entanto, aos deslocamentos onto-epistêmicos provocados pela opção por uma ou outra interpretação. Essa questão se encontra amplamente discutida no decorrer da obra de Brisson, 1998.

3 "[...] une modification de la conception de la nature du démiurge entraîne une révision complète de l'ontologie platonicienne." 
Essa distinção se faz necessária uma vez que da falta de conhecimento da existência dessas duas vertentes pode-se decorrer uma série de incompreensões do Timeu que, de outra forma, poderiam ser sanadas logo de início. Como já dissemos, procuraremos nos guiar pela linha interpretativa não-literal do texto.

\section{Pressuposto onto-epistemológico}

Precisamos também, mesmo que minimamente, nos municiar de compreensão sobre a estrutura onto-epistemológica ${ }^{4}$ que estrutura a tese cosmológica platônica, para que, com isso, possamos melhor compreender a figura demiúrgica, objeto deste trabalho. Para isso, primeiramente falaremos sobre o propósito de Platão com a realização de uma cosmologia, e então adentraremos a estrutura onto-epistêmica a qual a narrativa contida no Timeu está inserida.

Segundo Brisson, "o escrutínio sobre a phýsis [presente no Timeu] parece colocar-se subordinado a um projeto ético, político e pedagógico" e que, portanto, "a investigação sobre a natureza surge como pressuposto para se pensar uma teleologia imanente ao cosmo organizado, condição para que o homem realize seu fim como ser inteligente". (BRISSON, 2001, p. 10. apud MANINI, 2014, p. 22, grifo nosso) ${ }^{5}$.

Com efeito, "é necessário voltar à origem do homem e à origem do mundo, e explicar como o homem, o microcosmo, pode encontrar seu lugar no microcosmo, o universo, que é simplesmente a imagem sensível do modelo inteligível." (BRISSON; MEYERSTEIN, 1995, p.18) ${ }^{6}$

A partir disso, começamos a entender o propósito platônico em vincular essas duas esferas filosóficas: a esfera ontológica e a epistemológica. Isso vale dizer que a primeira está fundamentada na segunda,

4 Não é nossa intenção neste trabalho abordar com a profundidade que os temas ontológico e epistemológico em Platão merecem, mas tão somente fornecer o mínimo necessário à elucidação de fatores que rodeiam o tema proposto e na medida em que nos permita compreender a figura do demiurgo.

5 PLATON. Timée - Critias. Traduction, introduction, notes et bibliographie par Luc Brisson. Paris: Flammarion, 2001.

6 "[...] it is necessary to go back to the origin of man and to the origin of the world, and to explain how man, this microcosm, finds his place within the macrocosm, the universe which is but the sensible image of an intelligible model." 
uma vez que a exposição cosmológica do Timeu se dá através de uma estrutura de linguagem puramente ontológica. (BRISSON, 1998)

O Timeu nasce da intenção de Platão em inserir valores ético-normativos indispensáveis ao homem e a cidade. No entanto, Platão, "desde muito cedo, viu que isso colocava um problema epistemológico primordial, o do conhecimento desses valores." (BRISSON, 1998. p. $110)^{7}$, o que levaria o filósofo a necessidade de fundamentar seu projeto epistemológico à esfera ontológica. Continuemos:

É por isso que ele deve distinguir entre um conhecimento sensível relacionado com coisas sensíveis e um conhecimento inteligível relacionado com formas inteligíveis. Além disso, para evitar que tudo isso seja um desfile pragmático, deve encontrar um fundamento natural nas esferas da ética e da epistemologia. Só uma cosmologia pode conseguir isso, que apresenta a constituição do mundo como a fabricação, por um demiurgo tomando um modelo a partir de formas inteligíveis e informando um ambiente espacial indefinido, da alma e do corpo do todo onde o homem vive conhecendo e se determinando eticamente. (BRISSON, 1998. p. 110, grifo nosso) ${ }^{8}$

Segundo Brisson, Platão julgou indispensável que os valores normativos de uma cidade ideal estivessem naturalmente fundamentados na ética e epistemologia, e foi por isso que buscou essa fundamentação a partir de uma cosmologia; donde o Timeu surge como uma sistematização dessa última.

Trazendo objetivamente essa problemática onto-epistêmica para o Timeu, ainda na introdução epistemológica em $27 \mathrm{~d} 5$, encontramos a abertura dessa distinção: "Na minha opinião, temos primeiro que

7 "[...] très tot, il s'aperçoit que cela pose un problème épistémologique primordial, celui de la connaissance de ces valeurs."

8 "Voilà pourquoi il doit distinguer entre une connaissance sensible portant sur les choses sensibles et une connaissance intelligible portant sur les formes intelligibles. En outre, pour éviter que tout cela ne soit qu'une parade pragmatique, il doit trouver un fondement naturel aux sphères de l'éthique et de l'épistémologie. Seule une cosmologie peut y parvenir, qui présente la constitution du monde comme la fabrication, par un démiurge prenant modèle sur les formes intelligibles et informant un milieu spatial indéterminé, de l'âme et du corps du tout où vit l'homme connaissant et se déterminant éthiquement."

Revista Páginas de Filosofia, v. 9, n. 2, p. 35-57, jul.-dez. 2020 
distinguir o seguinte: o que é sempre e não devém, e o que é aquilo que devém, sem nunca ser?" (Tim., 27d5-28a1).

É importante que pré-estabeleçamos essa condição ontológica, visto que é à luz dessa divisão entre "o que é" e "o que devém", que a atuação do demiurgo se desenrola ao longo de todo o discurso do Timeu. 0 demiurgo, nesse sentido, serve como uma espécie de "agente atuante", responsável por realizar ativamente a "ligação", através do trabalho - metaforicamente - artesanal, entre aquele que é o mundo inteligível e aquele que é o mundo sensível, no momento em que atua na fabricação do mundo sensível sob a diretriz de um modelo inteligível. Ele é, por isso, em última instância, a figura que permite com que Platão leve a cabo seu projeto ético e epistemológico através da cosmologia.

Ainda em 28a1-4, dessa distinção ontológica surge a necessidade de uma segunda distinção, só que esta de cunho epistemológico, que é a forma como cada um desses dois níveis podem ser apreendidos: se pela razão, ou se pelos sentidos. Vejamos: "Um pode ser apreendido pelo pensamento com o auxílio da razão, pois é imutável. Ao invés, o segundo é objeto da opinião acompanhada da irracionalidade dos sentidos e, porque devém e se corrompe, não pode ser nunca." (Tim., 28a1-4)

Ou seja, da distinção ontológica entre o inteligível e o sensível, nasce a distinção epistemológica entre saber (epistêmê) e opinião (doxa), estando a primeira destinada ao que é sempre e a segunda ao que devém. (LOPES, 2011).

Vemos nesta seção que para compreender a figura do demiurgo é necessário compreender os pressupostos ontológicos e epistemológicos aos quais o diálogo do Timeu está estruturado, uma vez que, tanto a presença como a atuação do demiurgo articulam-se direta e correspondentemente a essa estrutura.

\section{Discurso verossímil}

Estabelecidos os conceitos, cada qual, doxa e epistêmê, à sua correspondente natureza, resta-nos, ainda, investigar sobre a natureza verossímil do discurso.

0 personagem Timeu, antevendo a problemática epistemológica do discurso que se propõe a fazer, estabelece-nos o pressuposto onto- 
-epistêmico no proêmio do diálogo, a saber: um discurso de verossimilhança (eíkos lógos) ${ }^{9}$, pois que “os discursos são congéneres daquilo que explicam.

Portanto, ó Sócrates, se no que diz respeito a variadíssimas questões sobre os deuses e sobre a geração do universo, não formos capazes de propor explicações perfeitas e totalmente concordantes consigo mesmas, não te admires. Mas se providenciarmos discursos verossímeis que não sejam inferiores a nenhum outro, é forçoso que fiquemos satisfeitos, tendo em mente que eu, que discurso, e vós, os juízes, somos de natureza humana, de tal forma que, em relação a estes assuntos, é apropriado aceitarmos uma narrativa verossímil e não procurar nada além disso. (Tim., 29c4 - d1, grifo nosso)

Ou seja, visto que o mundo criado é uma imagem (eikôn), o discurso ou narrativa sobre ele terá necessariamente esta mesma natureza." (LOPES, 2011, p 52).

A partir daqui introduzimos uma interessante relação de analogia entre o trabalho mimético de produção do demiurgo e o trabalho mimético discursivo do filósofo, cada qual estabelecido em um nível:

Num primeiro nível mimético, o demiurgo imita um modelo de inteligibilidade externo (as Ideias) cujas propriedades enforma na matéria pré-cósmica. No outro, o discursivo, é o filósofo que produz uma explicação através da observação esquemática do real, isto é, da imitação da ordem estabelecida pelo demiurgo. Então, a manifestação discursiva da criação há-de ser também ela de carácter mimético, isto é, do âmbito do verossímil, posto que o resultado (o mundo) é igualmente de natureza mimética: a soma dos particulares em processo, isto é, o devir, consiste numa constante imitação do modelo inteligível (as Ideias), cujo padrão de racionalidade espelha o plano cosmológico original e se desvela à observação analítica do filósofo. (LOPES, 2011, p. 52-53)

Brisson também encontra fundamentação do discurso mítico a partir da definição de sofismas encontrada no Sofista como "a arte

9 Quanto às implicações da distinção entre as expressões "discurso verossímil" (logous eikotas) e "narrativa verossímil" (eikos mythos), assim como o estatuto de verossimilhança do discurso, ver Lopes, 2011, pp. 48-53. Introdução.

Revista Páginas de Filosofia, v. 9, n. 2, p. 35-57, jul.-dez. 2020 
da produção humana de simulacros por mimetismo" que ajuda-nos a determinar "o significado e a natureza da produção divina no Timeu". (BRISSON, 1998, p.103) ${ }^{10}$

0 que precisamos ter em mente é que, se por um lado Timeu descreve "a produção divina das próprias coisas naturais" (BRISSON, 1998, p. 103) e por outro "a produção divina das imagens que acompanham cada uma dessas coisas" essa produção divina, ainda assim, "escapa a qualquer descrição" (p. 104) ${ }^{11}$ :

Tal descrição é inefável porque o vocabulário humano, seja ele de qualquer natureza, foi criado por e para os homens, e por isso mesmo só pode descrever a produção humana. Além disso, o discurso implica temporalidade, ou seja, uma descrição demiúrgica de produção que ocorre dentro de um processo temporal, ao passo que essa produção em si se situa além do tempo uma vez que é sua causa ${ }^{12}$. (BRISSON, 1998, p. 104) ${ }^{13}$

Com base nisso, Brisson conclui que somente recorrendo ao mito para que consigamos descrever essa produção divina. (BRISSON, 1998)

Dito isso, tudo fica claro. 0 domínio do Timeu é plausível, pois se trata de um diálogo cosmológico relativo à constituição das coisas sensíveis. No entanto, dado que o discurso humano é, em si mesmo, inadequado para descrever a produção divina do mundo sensível, Platão usa o tipo de discurso que permite, de certa forma, contornar a dificuldade que este limite representa. É por isso que podemos dizer que o Timeu é um mito. Na verdade, ele descreve, por meio da produção humana, a

10 “[...] « l'art de la production humaine de simulacres par la mimétique » nous est d'un grand secours pour déterminer le sens et la nature de la production divine dans le Timée.

11 [...] le Timée décrit d'une part la production divine des choses naturelles [...] Et d'autre part, il décrit la production divine des images qui accompagnent chacune de ces choses. [...] Cependant, cette production divine échappe à toute description."

12 Conforme vimos na seção anterior sobre a discussão da literalidade ou não-literalidade do texto.

13 "D'une part, elle est ineffable, car le vocabulaire humain, de quelque nature qu'il soit, a été créé par et pour les hommes et ne peut décrire, de ce fait, que leur production. D'autre part, le discours implique la temporalité, alors que la production du démiurge se situe au-delà du temps puisqu'elle en est la cause."

Revista Páginas de Filosofia, v. 9, n. 2, p. 35-57, jul.-dez. 2020 
produção divina do mundo sensível. 0 que é de fato um mito plausível. (BRISSON, 1998, p.105, grifo nosso) ${ }^{14}$

Mas para que essa concepção do mito não caia em engano, ele distingue dois tipos de mitos presentes em Platão: aquele o qual Platão critica em diversos momentos de seu diálogos, daquele que "tem

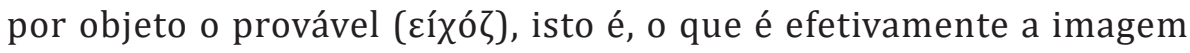

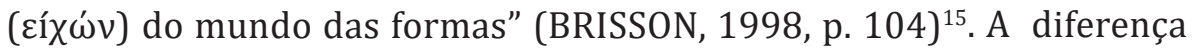
do segundo tipo é que este contém plausibilidade, o que dá o tom de formalidade e credibilidade aos discursos:

Mas os textos são formais sobre o assunto. Devemos considerar o Timeu, acima de tudo, um discurso plausível. É claro que esse discurso é de um tipo especial, pois expressa temporalmente o atemporal. Portanto, só pode ser um mito. [...] Mas um mito provável, cujo domínio é o das coisas sensíveis que, embora não possuam nem imobilidade nem certeza, as formas inteligíveis ainda possuem uma certa estabilidade e um certo grau de credibilidade. (BRISSON, 1998, p.105) ${ }^{16}$

Ou seja, vimos que a obra do Timeu, sobretudo, se trata de um discurso verossímil, que busca na medida do possível e dentro das limitações a que o objeto de investigação impõe, exprimir uma figura e sua atuação mimético-produtiva, cujo estatuto ontológico está além

14 “Ceci étant dit, tout s'éclaire. Le domaine du Timée est le vraisemblable, puisqu'il s'agit d'un dialogue cosmologique ayant trait à la constitution des choses sensibles. Cependant, étant donné que le discours humain est, en soi, impropre à décrire la production divine du monde sensible, Platon use du type de discours qui permet, d'une certaine façon, de contourner la difficulté que pose cette limite. Voilà pourquoi on peut dire que le Timée est un mythe. En effet, il décrit, par l'intermédiaire de la production humaine, la production divine du monde sensible. Ce qui est en fait un mythe vraisemblable."

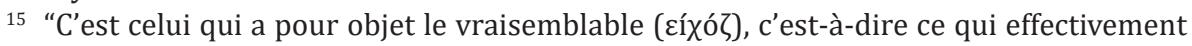
est l'image ( $\varepsilon i ́ \chi \omega \omega v)$ du monde des formes intelligibles."

16 "Mais les textes sont formels à ce sujet. Il faut tenir le Timée, avant tout, pour un discours vraisemblable. Certes, ce discours est d'un type spécial, car il exprime temporellement l'atemporel. Il ne peut, de ce fait, qu'être un mythe. [...] Mais un mythe vraisemblable dont le domaine est celui des choses sensibles qui, quoiqu'elles ne possèdent ni l'immobilité ni la certitude des formes intelligibles présentent tout de même une certaine stabilité et un certain degré de crédibilité."

Revista Páginas de Filosofia, v. 9, n. 2, p. 35-57, jul.-dez. 2020 
da possibilidade humana de apreensão, fazendo-se necessário, por isso mesmo, recorrer ao mito provável.

\section{O DeMiURgo}

\subsection{Elementos e características concernentes ao Demiurgo}

Neste capítulo trataremos de expor as principais características e elementos formativos da figura demiúrgica. De acordo com Brisson ${ }^{17}$, trata-se de uma necessidade importantíssima estudar o demiurgo, uma vez que a concepção de sua natureza implica a compreensão da própria ontologia platônica, chegando até mesmo a denominá-lo de "pedra angular da estrutura ontológica subjacente ao Timeu e essencial tanto no Sofista quanto no Filebo, além de estar implícita na Política e nas Leis" (1998, p, 29) ${ }^{18}$.

Ainda que seja possível encontrar em outros diálogos a concepção de um demiurgo universal, como por exemplo na República, ${ }^{19}$ como o artífice dos nossos sentidos (507c) e do conjunto do céu (530a), "o caráter do demiurgo só existe com consistência real em Platão no Ti$m e u$, onde as distinções entre o mundo das formas inteligíveis e o das coisas sensíveis aparecem claramente marcadas, entre a necessidade

${ }_{17}$ Na principal obra que estamos utilizando neste trabalho, Le même et l'autre dans la structure ontologique du Timée de Platon: un commentaire systématique du Timée de Platon, 1989, Brisson dedica um capítulo inteiro a análise da figura do demiurgo e busca tornar "concretamente inteligível o uso feito por Platão da figura do demiurgo" (p. 30) a fim de garantir os fundamentos ontológicos platônicos. Para isso, ele traça um esboço de sua figura dividindo-a em dois grandes aspectos: o aspecto prático e aspecto teórico do demiurgo. Além disso, ele busca encontrar uma posição síntese do demiurgo a partir desses dois aspectos dentro da estrutura geral em que ele se insere. Deteremo-nos apenas a alguns aspectos práticos do demiurgo. Quanto ao seu aspecto teórico, essa parte pode ser estudada nas páginas 55 a 64, 1998, onde Brisson analisa o desaparecimento e reaparecimento no médio platonismo e neoplatonismo da figura demiúrgica.

18 "[...]la clef de voûte de la structure ontologique qui sous-tend le Timée et qui s'impose aussi bien dans le Sophiste que dans le Philèbe, en plus d'être implicite dans le Politique et dans les Lois."

19 República, livros VI e VII, em 507c e 530a e também no livro X

Revista Páginas de Filosofia, v. 9, n. 2, p. 35-57, jul.-dez. 2020 
mecânica e a finalidade transcendente." (BRISSON, 1998, p. 56) ${ }^{20}$. Além disso, é no Timeu que encontramos a mais bela exposição de sua figura. Vejamos o trecho que descreve aquele que é a causa (aitia) do universo:

Ele era bom, e no que é bom jamais nasce inveja de qualquer espécie. Porque estava livre de inveja, quis que tudo fosse o mais semelhante a si possível. Quem aceitar de homens sensatos que esta é a origem mais válida do devir e do mundo estará a aceitar o raciocínio mais acertado. Na verdade, o deus quis que todas as coisas fossem boas e que, no que estivesse à medida do seu poder, não existisse nada imperfeito. Deste modo, pegando em tudo quanto havia de visível, que não estava em repouso, mas se movia irregular e desordenadamente, da desordem tudo conduziu a uma ordem por achar que esta é sem dúvida melhor do que aquela. Com efeito, a ele, sendo supremo, foi e é de justiça que outra coisa não faça senão o mais belo. (Tim., 29d7 - 30a9)

O demiurgo é um deus bom e absolutamente livre de inveja, e por ser bom o seu propósito não é outro senão o de produzir coisas boas, construindo um mundo tão belo quanto sua natureza o permite. Sendo, portanto, a melhor das causas. Dessa forma, a narrativa mítica adquire um caráter teleológico.

Ele é o divino construtor que impõe ordem ${ }^{21}$ no caos da matéria preexistente a fim de gerar o universo ordenado e belo. No entanto, o demiurgo se instrui por uma modelo imutável e eterno:

Ora, se o mundo é belo e o demiurgo é bom, é evidente que pôs os olhos que é eterno; se fosse ao contrário - o que nem é correto supor -, teria posto os olhos no que devém. Portanto, é evidente para todos que pôs os olhos no que é eterno, pois o mundo é a mais bela das coisas devenientes e o demiurgo é a mais perfeita das causas. (Tim., 29a 2-8)

20 “[...] le personnage du démiurge n'existe avec une consistance véritable chez Platon que dans le Timée où apparaissent bien marquées les distinctions entre le monde des formes intelligibles et celui des choses sensibles, entre nécessité mécanique et finalité transcendante [...]"

210 aspecto matemático no processo ordenativo da matéria disforme é fortemente marcado no Timeu. A formação de um mundo ordenado, à imagem do modelo, obedece a medidas, proporções matemáticas e progressões geométricas. Dessa forma, o demiurgo atua tornando o universo um todo simétrico, harmônico e ordenado. Para estudo aprofundado da exposição matemática no Timeu, ver Brisson, 1998, pp. $314-332$.

Revista Páginas de Filosofia, v. 9, n. 2, p. 35-57, jul.-dez. 2020 
Trata-se do arquétipo ou Ideia (eidos), oriundo, evidentemente, do mundo inteligível. Sendo um "construtor", o demiurgo empreende uma atividade mimética ${ }^{22}$ ao criar o mundo sensível a partir da imitação desse modelo, que é um arquétipo. Esse ato faz com que o demiurgo assemelhe-se grandemente a um artífice, que "antes de produzir alguma coisa, tem em conta uma forma da qual assimilará as propriedades que fará corresponder no material que trabalha." (LOPES, 2011, p. 39). Vemos, com isso, que o demiurgo realiza sua obra através de intelecção e atuação, conforme bem definido por Bittar:

O Demiurgo contempla e produz, existindo nele atividades teórica e prática inseparáveis. Ele não seria um simples artesão, mas aquele que produz transferindo para as cópias as virtudes de um modelo. 0 Demiurgo visa à Ideia do $\mathrm{Bem}^{23}$ e a espelha na criação. (BITTAR, 1977, p. 28)

Neste ponto da exposição se faz importante ressaltar que a ação do demiurgo parece ser duplamente limitada: tanto pelo modelo inteligível e imutável ao qual ele precisa fixar o olhar enquanto mimeticamente reproduz na matéria o simulacro desse mesmo modelo, quanto pela própria condição de caos e desordem a que essa matéria está sujeita.

Essa condição corrobora com a tese de Brisson ao dizer que há limitações e impotências que caracterizam a figura e a atuação do demiurgo, e que, inclusive, a condição de antropomorfismo e poliformismo as quais sua figura está sujeita são relativas à essas limitações:

${ }^{22}$ Aprofundando ainda mais a "caracterização da obra do demiurgo como uma actividade mimética" Lopes propõe que "tenhamos em conta [...] que esta figura, em termos muito gerais, é um fabricador", uma vez que essa concepção está apoiada no termo poiêtês, que aparece em 28c3. Não obstante a tradução "poeta" não possa ser totalmente aceita, ainda assim, a atividade de criação poética contém algumas características semelhantes ao processo criativo realizado pelo demiurgo, uma vez que ela é mimética. (LOPES, 2011)

${ }^{23}$ Consideramos que o demiurgo não pode ser identificado à Ideia do Bem, mas tão somente que se instrui por ela ao fabricar o mundo à sua imagem. Sobre isso, Brisson diz que o Bem é a causa do Noûs, e que "o demiurgo desempenha, em relação ao mundo sensível, o mesmo papel que o bem em relação ao mundo inteligível." (BRISSON, 1998, p. 74) 
[...] o produtor não é investido de todo poder. [...] o demiurgo, aquele que fabrica ou o universo ou um objeto qualquer, vê sua ação limitada, tanto pela natureza dos materiais que ele utiliza como pelas exigências do modelo que ele se aplica em reproduzir". (BRISSON, 2003, p. 264)

Brisson também identifica que o demiurgo "raciocina' ou "tudo simplesmente 'reflete"24 (1998, p. 33), "leva em consideração"25, e, "uma vez que fazer um ato de pensamento constitui, para Platão, a condição sine qua non da linguagem, não é de surpreender que o demiurgo fale" $^{26}\left(1998\right.$, p. 33) ${ }^{27}$. Somado à isso, como já mencionado, a figura do demiurgo é tão fortemente marcada pelo antropomorfismo que chega até mesmo ter sentimentos "quando se apercebe de que a sua obra estava a tomar o rumo certo, já que representava com bastante verossimilhança o arquétipo, rejubilou e ficou satisfeito" (Tim., 37c7). ${ }^{28}$

Uma definição ainda mais próxima da natureza do demiurgo estaria em 28c3-4 em que o personagem Timeu o define como "criador e pai do mundo". Essa definição faria aproximar mais ainda o demiurgo a uma figura antropomórfica. No entanto, os autores não-literais compreendem essa frase "à luz do carácter mimético da demiurgia, e, por outro lado, de acordo com esta função ordenadora; ou seja, será 'pai' como educador e não como princípio de geração", ademais, como "o arquétipo a que o filósofo deve aspirar." (LOPES, 2011, p. 42). Portanto, mesmo mediante a essa definição: "criador e pai de tudo", Brisson é categórico ao afirmar: "ainda que distinta, a figura do demiurgo não apresenta nada individual. Aparece, acima de tudo, como investido de caráter impessoal e coletivo. Em suma, o demiurgo não é um indivíduo, mas uma função." (BRISSON, 1998, p. 32) ${ }^{29}$. Sua funcionalidade estaria

${ }^{24}$ Cf. Tim., 30 b l, 34 a 8, 52 d 2, 55 c 7.

25 Cf. Id., 33 b 7

26 Cf. Id., 41 a 5-6, d 4, e 3, etc.

27 "[...] «raisonne» ou tout simplement «réfléchit». [...] « prend en considération». [...] puisque faire l'acte de pensée constitue, pour Platon, la condition sine qua non du langage, il n'est pas surprenant que le démiurge parle."

28 Para uma análise aprofundada dos elementos psicológicos do demiurgo, ver Brisson, 1974, pp. 33-35, a partir de uma minuciosa análise semântica dos termos em grego.

29 "[...] même distincte, la figure du démiurge ne présente rien d'individuel. Elle apparaît, avant tout, comme investie d'un caractère impersonnel et collectif. En un mot, le démiurge n'est pas un individu, mais une fonction." 
atrelada a ideia de uma estrutura hierárquica" ${ }^{30}$ "envolvendo uma certa proporcionalidade entre a natureza das demiurgias e a dos seres a serem produzidos." (BRISSON, 1998, p. 32) ${ }^{31}$

No que diz respeito às atividades da figura demiúrgica, Brisson faz um minucioso trabalho ao comparar suas funções demiúrgicas àquelas pertinentes a terceira e primeira classe da cidade platônica ${ }^{32}$. Seguindo esse escopo é levado em consideração "nas várias operações do demiurgo, a descrição das operações técnicas específicas de diversos negócios" (BRISSON, 1998, p.32) ${ }^{33}$ a fim de que o demiurgo dê cabo ao seu processo de construção do mundo. As operações relativas à terceira classe são: metalurgia, construção, cerâmica, pintura, modelador de cera, trança, agricultura. Além dessas, há ainda aquelas duas relativas à primeira classe: colonização e persuasão.

A exemplo, vejamos como servem as analogias associadas ao trabalho manual do artesão:

De fato, o Demiurgo produz a "Alma do Mundo", a "alma humana" e a "alma vegetativa" utilizando técnicas de metalurgia (35a-b, 41d, 77a); constitui o "Corpo do Mundo" como uma construção (semelhante a construção de prédios: 34b, 36d-e); na produção da esfericidade do "Corpo do Mundo" (33b), na fabricação dos ossos (73e) e do esqueleto (73e-74a) utiliza técnicas de cerâmica. Além disso, é qualificado de modelador de cera (74c) e conhecedor da arte de entrançar (78b-c). (BITTAR, 1977, p. 29)

Quanto às funções pertinentes à primeira classe platônica, essas são análogas à ação do demiurgo ao fundar uma cidade e também como mestre da persuasão quando ordena a matéria disforme. A explicação dessa tese está em Brisson (1998, p.50) ao explicar a ambivalência do

30 o demiurgo cria uma hierarquia de demiurgos menores, cujo trabalho é o de fabricação dos seres mortais.

31 "[...] impliquant une certaine proportionnalité entre la nature des démiurgies et celle des êtres a produire."

32 Para o estudo completo de cada função demiúrgica concernentes à terceira e primeira cidade platônica ver Brisson, 1974, pp 35-54

33 [...] dans les diverses opérations du démiurge, la description d'opérations techniques propres à plusieurs métiers" 


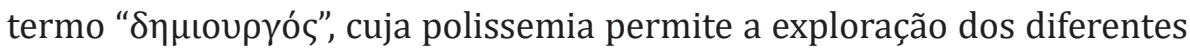
aspectos da figura demiúrgica:

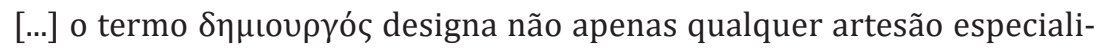
zado em metalurgia, construção, pintura, modelagem em cera e trança, mas também, na Grécia Ocidental, um magistrado muito importante.

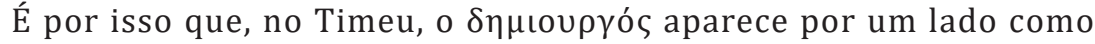
colonizador ou fundador de uma cidade, e por outro como mestre da persuasão. Essas duas últimas funções, longe de se relacionarem com o artesanato que, ligado à agricultura, define a terceira classe da cidade platônica, teriam mais afinidade com a primeira classe, a dos filósofos-governantes. Pode parecer estranho, mas o uso bivalente do termo

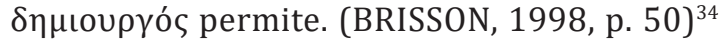

Vemos, portanto, que Platão atribui ao demiurgo aquele que desempenha não somente a função de fabricação do mundo, mas também de magistrado, governança, legislação, e mestre da persuasão.

Brisson compreende que a metáfora de um demiurgo organizador de um ambiente espacial disforme, que fixa os olhos nos modelos que constituem as formas inteligíveis para produzir as imagens que são as coisas sensíveis, "comanda uma visão ontológica que envolve uma estrutura de quatro termos: voũs demiúrgico, formas inteligíveis, coisas sensíveis e ambiente espacial" (BRISSON, 1998, p. 29) 35; e conclui que "o demiurgo não pode ser um voũ separado, distinto das formas inteligíveis, do meio espacial e de seu produto, o mundo sensível." (BRISSON, 1998, p. 29) ${ }^{36}$. Portanto, o demiurgo está inserido num con-

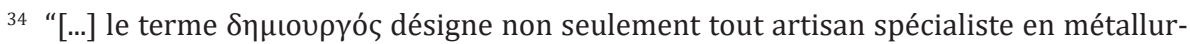
gie, en construction, en peinture, en modelage de cire et en tressage, mais aussi, en Grèce occidentale, un magistrat très important. Voilà pourquoi, dans le Timée,

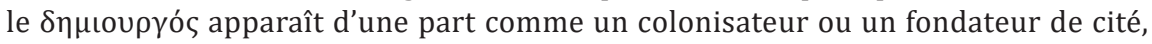
et d'autre part comme un maître de la persuasion. Ces deux dernières fonctions, loin de se rapporter à l'artisanat qui, relié à l'agriculture, définit la troisième classe de la cité platonicienne, auraient plus d'affinité avec la première classe, celle des philosophes-gouvernants. Cela peut paraître bizarre, mais l'emploi bivalent du terme $\delta \eta \mu$ เouprós permet la chose."

35 "[...] commande une vision ontologique impliquant une structure à quatre termes: voũs démiurgique, formes intelligibles, choses sensibles et milieu spatial."

36 “[...] le démiurge ne peut être qu'un voũ séparé, distinct des formes intelligibles, du milieu spatial et de son produit, le monde sensible."

Revista Páginas de Filosofia, v. 9, n. 2, p. 35-57, jul.-dez. 2020 
texto ontológico, e figura e seu trabalho são justificados pela lacuna existente entre as formas inteligíveis e o ambiente espacial:

Suas atividades, relacionadas a funções específicas da terceira ou da primeira classe da cidade platônica, devem ser destacadas levando-se em consideração precisamente o contexto ontológico de que acabamos de falar. Não é indiferente que o demiurgo "trabalhe", seja qual for a natureza desse trabalho. Este trabalho implica, de fato, uma lacuna entre o mundo das formas inteligíveis e o ambiente espacial, e toma como certa a distinção entre o produtor e seu produto. (BRISSON, 1998, p. 29) ${ }^{37}$

Não é nosso intuito apresentar uma descrição aprofundada das funções aqui apontadas, mas tão somente citá-las, a fim de que possamos extrair uma percepção, através da metáfora do deus-artesão, quanto à atuação de construção tomada pelo demiurgo. A metáfora das funções demiúrgicas, como um "artesão que trabalha o metal, que constrói e monta, que amassa e modela a argila, que pinta, que dá

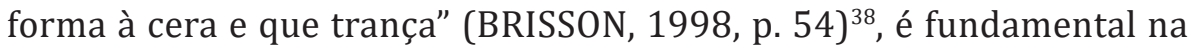
explicação da fabricação cosmológica.

Com isso, fechamos essa parte da delineação das principais características e elementos concernentes ao demiurgo. Vemos que o demiurgo, "criador e pai de tudo", é instituído como um deus bom que, através das funções artesanais, e sempre de olho no modelo inteligível, eterno e perfeito, fabrica o cosmos a partir da matéria disforme a fim de torná-lo, tal como o modelo, o mais perfeito, bom e belo possível; apesar das limitações que de antemão lhe estão impostas. Ainda que não possa ser considerado um indivíduo, mas uma função, o demiurgo apresenta características antropomórficas ao ser caracterizado como um artesão, e também no que tange o aspecto "psicológico" quando pensa, tem von-

37 "Ses activités, relevant des fonctions propres soit à la troisième, soit à la première classe de la cité platonicienne, doivent être mises en lumière en tenant compte précisément de l'arrière-plan ontologique dont nous venons de parler. Il n'est pas indifférent que le démiurge " travaille », quelle que soit la nature de ce travail. Ce travail implique, en effet, un écart entre le monde des formes intelligibles et le milieu spatial, et prend pour acquis la distinction entre le producteur et son produit."

38 "[...] un artisan qui travaille le métal, qui construit et assemble, qui pétrit et modèle l'argile, qui peint, qui donne une forme à la cire et qui tresse."

Revista Páginas de Filosofia, v. 9, n. 2, p. 35-57, jul.-dez. 2020 
tade e experimenta sentimentos. Essa constatação leva-nos a uma outra questão fundamental à sua figura, a de que, acima de tudo, o demiurgo é um Noûs (voũc). ${ }^{39}$ Sobre este tema é o que iremos discorrer agora.

\subsection{O Demiurgo como Noûs}

No Timeu, "a inteligência é reconhecida como um princípio da natureza.” (BRISSON, 1998, p. 56) ${ }^{40}$. Porém, não apenas no Timeu mas em outros diálogos Platão faz referência ao intelecto/inteligência (noûs) como princípio ordenador cósmico e causa de todas as coisas. A exemplo disso, encontramos no Fédon essa explicação de Sócrates ao recorrer a teoria de Anaxágoras:

[...] que a mente é organizadora e a causa de tudo, fiquei satisfeitíssimo com semelhante causa, por parecer-me, de algum modo, muito certo que a mente fosse a causa de tudo, tendo imaginado que, a ser assim mesmo, como coordenadora do Universo, a mente disporia cada coisa em particular pela melhor maneira possível. (Féd., 97c 2-7)

Especificamente nesse trecho, apesar de não se tratar da ação de um criador, conforme aponta Karfik (2007), encontra-se aí "muito claramente formulada, uma concepção do intelecto como princípio de ação, tanto antropológica quanto cosmologicamente." (p. 04) ${ }^{41}$

Brisson também aponta-nos o aparecimento do noûs em outros diálogos platônicos que apoiam a interpretação do demiurgo como noûs: "No Filebo, o noûs é o rei do céu e da terra ${ }^{42}[\ldots]$. Nas Leis, lemos que o noûs é o verdadeiro mestre de todas as coisas ${ }^{43}$, e que ele dirige o universo ${ }^{44 "}$. (BRISSON, 1998, p. 76) ${ }^{45}$

39 Noûs (voũc): termo filosófico grego que tem por significado "intelecto"; "inteligência". PETERS, F. E. Termos Filosóficos Gregos: um léxico histórico. Tradução: Beatriz Rodrigues Barbosa. 2. ed. Lisboa. Fundação Calouste Gulbenkian, 1967. 112 p.

40 "[...] l'intelligence était reconnue comme principe de la nature [...]"

41 "[...] formulée d'une manière très nette, une conception de l'intellect en tant que principe de l'action tant sur le plan anthropologique que sur le plan cosmologique."

42 Filebo, 28 c 7-8.

43 Leis, 875 с 6 - d 3

44 Idem, 966 e 2-4.

45 "Dans le Philèbe, le voũs est le roi du ciel et de la terre [...]. Dans les Lois, on lit que le voũs est le véritable maître de toutes choses, et qu'il dirige l'univers." 
Enfim, extenso é o número de interpretações que identificam o demiurgo ao noûs, e no Timeu fica claro que "o demiurgo é um noûs que ordena a necessidade ${ }^{46}$ pela persuasão." (BRISSON, 1998, p. 76) ${ }^{47}$ 0 que acabamos de passar em revista, à exceção de pequenos aspectos, ilustra o que foi fabricado pelo Intelecto. É necessário que justaponhamos ao discurso aquilo que foi pela Necessidade e Intelecto. Mas, como o Intelecto dominava a Necessidade, persuadindo-a a orientar para o melhor a maioria das coisas devenientes, foi deste modo (através da cedência da Necessidade a uma persuasão racional) que o universo foi constituído desde a sua origem" (Tim., 47e 6 - 48a 7).

Além do intelecto, no entanto, fica explícito nesse trecho que o universo é produto de uma combinação entre Intelecto e Necessidade (anánke). Segundo Cornford ${ }^{48}$ (1935), a natureza e posição do demiurgo não podem ser determinadas sem considerar essa combinação.

A Necessidade, já citada no capítulo anterior como elemento de limitação ao demiurgo, aparece na segunda parte do Timeu em $47 \mathrm{e}$ -69a e está intimamente ligada ao o noûs divino, já que se encontra em oposição à razão demiúrgica que busca ordenar a matéria em estado de caos preexistente.

Segundo Cornford, a necessidade é "persuadida" pela razão, porque ao demiurgo cabe, tanto quanto possível, assumir e reduzir a Necessidade e o caos dos movimentos. Segundo ele:

Necessidade e o caos representados como fatores no mundo visível que confrontam a inteligência divina, como os materiais dados que o artesão humano deve usar da melhor maneira possível, embora suas propriedades possam não ser totalmente adequadas ao seu propósito. (CORNFORD, 1935, p. 35) ${ }^{49}$

46 Devemos entender a Necessidade enquanto matéria; a matéria disforme e em caos que o demiurgo deve ordenar.

47 [...] le démiurge est un voũs qui ordonne la nécessité par la persuasion."

48 Cornford é bastante citado por Brisson e, assim como este, é adepto da linha não-literal de interpretação.

49 "Necessity and chaos are represented as factors in the visible world which confront the divine intelligence, like the given materials which the human craftsman must use as best he can, though their properties may not be wholly suitable to his purpose." 
Evidenciamos, portanto, que a inteligência divina simbolizada pelo demiurgo dá resultado ao bom ordenamento cósmico: "Assim, tal como o intelecto percebe as formas do ser que é - tantas quantas há nele -, o demiurgo olhou para baixo e decidiu que o mundo deveria ter tantas formas quantas aquele tem." (Tim., 39e 9-13)

Ainda uma outra questão que surge ao tratarmos do demiurgo enquanto noûs, é a discussão entre a inerência do noûs na alma e o noûs enquanto existência independente ${ }^{50}$. A origem da discussão se encontra no trecho em que o demiurgo fabrica a alma do mundo (34b 3) para que o mundo possa adquirir intelecto, uma vez que "seria impossível que o intelecto se gerasse em algum lugar fora da alma." (Tim., 30b 4-5).

Apesar da ambiguidade interpretativa a que esse trecho da obra possa induzir, é essencial discernir que "Timeu não diz que não pode haver intelecto sem alma; colocada em seu contexto, esta frase diz que, para poder participar da faculdade do intelecto, uma coisa visível, isto é, corporal, deve necessariamente ser dotada de uma alma" (KARFIK,

50 A questão da alma é introduzida em 30b 5 e é motivo de grandes controvérsias quando se busca encontrar seu lugar ontológico com relação ao demiurgo. Segundo Brisson, intérpretes que defendem a primeira hipótese, da inerência do noûs na alma, como Cherniss, por exemplo, entendem o "voũ como o resultado na alma do 'contato' da alma com as ideias" (CHERNISS, ANO, p. 607 APUD BRISSON, 1998, p. 77), o que levaria a concluir que "o demiurgo deve ser a alma que possui o voũs, ou a alma iluminada por formas inteligíveis." (BRISSON, 1998, p. 77). Para o autor, as passagens e argumentos que sustentam essa tese permanecem inconsistentes e de forma alguma excluem a existência de um noûs separado, uma vez que se tratam exclusivamente sobre a alma do mundo. Pelo contrário, Brisson identifica a derradeira inconsistência de atribuir ao noûs demiúrgico identificação à alma do mundo, como se essa dotada fosse de existência independente e autônoma, na seguinte passagem do Timeu (30b 1-5): “Tendo, portanto, refletido (o demiurgo), ele percebeu que, das coisas visíveis por sua natureza, um todo desprovido de inteligência nunca poderia emergir que fosse mais bonito do que um todo inteligente. E, além disso, que o intelecto não pode nascer em nada, se estiver separado da alma. Em virtude dessas reflexões, foi depois de colocar o intelecto na alma e a alma no corpo, que ele deu forma ao mundo". Em última instância, "a alma não é um ser que tem uma existência independente e não derivada; não pode, portanto, ser considerada como a causa última de tudo no mundo

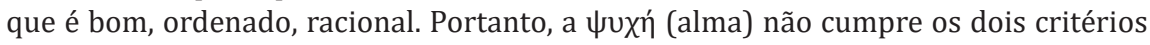
que permitiriam ser considerada um princípio demiúrgico." (BRISSON, 1998, p. 83). Para estudo completo ver pp. 76 - 84 da referida obra.

Revista Páginas de Filosofia, v. 9, n. 2, p. 35-57, jul.-dez. 2020 
2007, p. 4) ${ }^{51}$. Portanto, não há contradição na apresentação do demiurgo como um intelecto separado da alma, sendo esta última, apenas um de seus produtos. Vejamos como Brisson conclui essa questão ${ }^{52}$ :

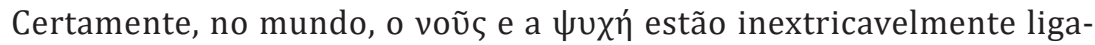

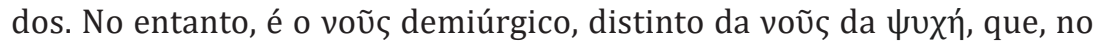

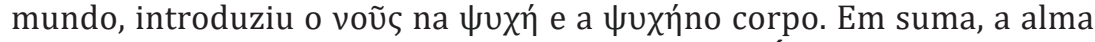
do mundo tem um voũs, e o demiurgo é um voũc. É aí que reside toda a diferença. [...] 0 demiurgo é, portanto, um voũ̧; separado, não $\psi u \chi \eta ́$. Porque apenas este voũ̧; separado preenche estas duas condições: ter uma existência independente e não derivada; e ser a fonte e a causa de tudo o que é bom, ordenado e racional no universo. (BRISSON, 1998, p. 84) ${ }^{53}$

Portanto, vemos que em toda a filosofia platônica as concepções de causa estão sempre ligadas ao princípio da inteligência ou razão. No entanto, é no Timeu que essa causa ganha forma sistematizada através da noção de um demiurgo como inteligência ordenadora dos cosmos. Essa inteligência é responsável por persuadir a Necessidade, que constitui objeto de limitação a fabricação demiúrgica, a fim do bom ordenamento cósmico. Além disso, ocorre não identificarmos a inteligência com a alma do mundo, uma vez que dessa identificação decorreria uma má interpretação do próprio estatuto ontológico do demiúrgico.

\section{CONSIDERAÇões FINAIS}

Com base no que foi exposto nesta pesquisa, vimos que o demiurgo é um deus-artesão que fabrica o cosmos, ou ainda, a causa orde-

51 Timée ne dit pas qu'il ne peut y avoir d'intellect sans une âme ; replacée dans le contexte qui est le sien cette phrase dit que, pour pouvoir prendre part à la faculté de l'intellect, une chose visible, c'est-à-dire corporelle, doit nécessairement être dotée d'une âme.

52 Ver Karfik, 2007, nota de rodapé 31, para conjunto bibliográfico de autores que defendem essa tese.

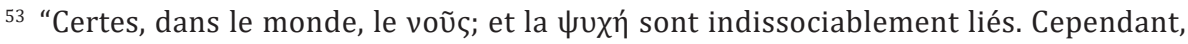
c'est le voũs démiurgique, distinct du voũs; de la $\psi u \chi \eta ́$, qui, dans le monde, a

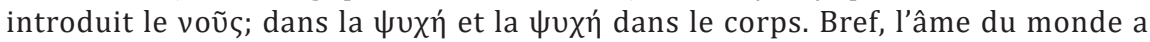
un voũs, et le démiurge est un voũ s. Là réside toute la différence. [...] Le démiurge est donc un voũs; séparé, et non $\psi u \chi \eta ̛$. Car seul ce voũs; séparé répond à ces deux conditions : avoir une existence indépendante et indérivée; et être la source et la cause de tout ce qui, dans l'univers, est bon, ordonné et rationnel."

Revista Páginas de Filosofia, v. 9, n. 2, p. 35-57, jul.-dez. 2020 
nadora do mundo visível a partir da deliberada intenção do Intelecto (noûs); visto que, a obra do Timeu se trata de um discurso verossímil para que se subtraia da figura demiúrgica e da metáfora artesanal, as quais Platão simbolizou miticamente, a atuação de uma inteligência ordenadora do cosmos.

A definição do demiurgo de "criador e pai do mundo" deve ser igualmente compreendida sob aspecto mimético do demiurgo, e, sob a linha de interpretação não-literal, entendido como educador e exemplo divino aos homens.

A efeito do papel de ingerência do demiurgo, o mundo é a sua causa pois ele tem sempre em vista aquilo que é eterno e perfeito, não constituindo ele próprio esse modelo, mas instruindo-se por ele ao fabricar o mundo sensível à imagem desse modelo. 0 demiurgo é causa do mundo sensível, portanto, no sentido de ordenar a matéria pré-existente, transmitindo-lhe a forma e os valores de bem, ordem e beleza que vê no modelo.

O demiurgo é bom, e, tendo a sua natureza boa, faz com que a sua criação seja tão boa quanto possível, não por uma limitação sua, mas pela limitação do material o qual modela.

0 mundo sensível ainda em estado de caos, é denominado de Necessidade, que constitui oposição e resistência a atuação intencional e ordenativa do noûs demiúrgico; esse fator constitui uma limitação ao demiurgo.

O demiurgo tem uma figura determinada, tanto ontologicamente onde aparece como um deus e causa do mundo sensível, quanto no nível psicológico onde ele age com vontade e pensamento e experimenta sentimentos. Apesar de possuir características psicológicas, como reflexão, pensamento e sentimentos, não constitui caráter pessoal, mas representa uma função. A atuação do demiurgo na ordenação do cosmos se dá por intermédio das diferentes funções de trabalho, análogas às funções da primeira e terceira cidade platônica.

É no Timeu que, além de ganhar forma consistente, é denominado como uma causa racional, inteligente. Não apenas isso, mas o demiurgo tem existência independente e não derivada, é um noûs separado da alma do mundo, sendo esta última um de seus produtos. 
Vimos também que, inevitavelmente, a epistemologia e a ontologia platônicas estão imbricadas na exposição cosmológica. A busca por uma definição e lugar ontológico do demiurgo dentro do corpus platônico entranha-se com o próprio método epistemológico pelo qual Platão se dispõe a explicar e figurar este personagem. A efeito disso, no que concerne à exposição de sua narrativa, temos um discurso verossímil.

Por último, de acordo com a linha não-literal que optamos prosseguir ao longo da pesquisa, a representação antropomórfica do demiurgo como deus-artesão deve ser entendida apenas como mítica, através de um discurso verossímil, para expressar a inteligência (nôus) do cosmos. Além disso, o surgimento da figura do demiurgo por Platão surge da necessidade de criar uma cosmologia que pudesse fundamentar a sua epistemologia, com vistas a inserir os valores éticos nos homens.

Essa última análise está em congruência com aquela interpretação que mencionamos, que o demiurgo, "criador e pai do mundo" serve como modelo, exemplo divino aos homens.

\section{REFERÊNCIAS}

\section{Fontes Primárias}

PLATÃo. Timeu. Introdução, tradução do grego e notas de Rodolfo Lopes. São Paulo: Annablume, 2012.

PLATÃO. Fédon. Trad. Carlos Alberto Nunes. Belém: Ed.ufpa, 2011.

PLATÃo. República. Trad. Ana Lia Amaral de Almeida Prado. São Paulo: Martins Fontes, 2006

\section{Fontes Secundárias}

BITTAR, Hildeberto. "Introdução". Em Platão. Timeu. Tradução de Carlos Alberto Nunes. Belém, Editora da Universidade Federal do Pará, 1997.

BRISSON, L. Le Même et l'Autre dans la structure ontologique du Timée de Platon (1974). Sankt Augustin: Verlag, 1998a.

BRISSON, L; MEYERSTEIN, W. Inventing the Universe: Plato's Timaeus, the Big Bang, and the problem of scientific knowledge (1991). New York: Suny, 1995.

BRISSON, L. Plato, the Myth Maker (1994). Trad. e intro. por G. Naddaf. Chicago and London: The University of Chicago Press, 1998b.

Revista Páginas de Filosofia, v. 9, n. 2, p. 35-57, jul.-dez. 2020 
BRISSON, L. Leituras de Platão (2000). Tradução de Sônia Maria Maciel, EdiPUCRS, 2003.

CORNFORD, F. M. Plato's Cosmology (1935). Indianapolis: Hacket, 1997.

Karfík, Filik. Que fait et qui est le démiurge dans le Timée ?. Études platoniciennes. 2007. Disponível em: <https://journals.openedition.org/etudesplatoniciennes/907> Acesso em 29. out. 2020

MANiNI, J. L. S. O DEUS ARTESÃO: O PAPEL DO DEMIURGO NO TIMEU DE PLATÃo. 2014. 130f. Dissertação (Mestrado em Filosofia) - Universidade Federal de Minas Gerais, Minas Gerais, 2014.

Revista Páginas de Filosofia, v. 9, n. 2, p. 35-57, jul.-dez. 2020 